\title{
Experimental fossilization of the RNA World in the presence of clay minerals
}

\author{
SYLVAIN BERNARD ${ }^{1}$, PIERRE JACQUEMOT ${ }^{2,3}$, ISIS \\ CRIOUET $^{3}$, JEAN-CHRISTOPHE VIENNET ${ }^{3}$ AND MAGUY \\ $\mathrm{JABER}^{2}$ \\ ${ }^{1}$ Institut de Minéralogie, de Physique des Matériaux et de \\ Cosmochimie, Sorbonne Université - CNRS - MNHN \\ ${ }^{2}$ LAMS - CNRS - Sorbonne Université \\ ${ }^{3}$ IMPMC - CNRS - MNHN - Sorbonne Université \\ Presenting Author: sbernard@mnhn.fr
}

The concept of the RNA World, which posits that the primary living substance was RNA or something chemically close, has recently gone from speculation to a prevailing idea [1]. The only way to confirm its reality would be to identify traces of the RNA World within the most ancient geological record. To help recognize these potential traces, we conducted experiments to simulate the fossilization of RNA in the presence of more-or-less crystalline $\mathrm{Fe} / \mathrm{Mg} / \mathrm{Al}$ smectitic clay minerals under pressure and temperature conditions typical of diagenesis. NMR, FTIR and STXM-XANES investigations revealed that the organic fraction of all the experimental residues is no longer RNA, nor the quite homogeneous aromatic-rich residue produced during experiments conducted in the absence of smectites [2], but rather consists of more-or-less N-rich organic compounds (including amide-rich compounds) associated/trapped to/into clay minerals [3-5]. Although RNA did not withstand diagenesis, clay minerals efficiently trapped organic carbon. Of note, results showed that the nature of the gas phase impacts the chemistry of the residual $\mathrm{N}$-rich organic compounds trapped within the interlayer spaces of smectites (e.g. mainly aliphatic-rich under $\mathrm{CO}_{2}$ vs dominated by heterocycles under $\mathrm{N}_{2} / \mathrm{O}_{2}$ ) [5]. In addition, rather than the pure smectites obtained in the absence of RNA, XRD, SEM and TEM data showed that the mineralogy of the experimental residues includes amorphous silica and aluminosilicates mixed together with nanoscales phosphates and clay minerals, the final organomineral assemblages being strongly dependent on the gas phase and on the nature of the initial mineral phase [3-5]. In a way, the degradation of RNA in the presence of smectites led to the precipitation of a quite uncommon mineral assemblage that could be seen as a biosignature per se. Altogether, these results highlight the importance of fine-scale mineralogical investigations when discussing the nature/origin of potential traces of the RNA World in ancient rocks.

[1] Higgs \& Lehman (2015), Nature Reviews Genetics 16, 7 17.

[2] Criouet et al. (2021), Geochemical Perspectives Letters 16, 40-46.

[3] Jacquemot et al. (2019), Scientific Reports 9, 20251.

[4] Viennet et al. (2019), Geochemical Perspectives Letters 12, 28-33.

[5] Viennet et al. (2020), Applied Clay Science 191, 105616. 